\title{
PENGARUH LOGOTERAPI MEDICAL MINISTRY TERHADAP DEPRESI DAN KUALITAS HIDUP PASIEN PASCA STROKE
}

\section{THE EFFECT OF MEDICAL MINISTRY LOGOTHERAPY ON DEPRESSION AND QUALITY OF LIFE POST-STROKE PATIENTS}

\author{
Sri Wahyuni Imron ${ }^{1}$, Aris Sudiyanto ${ }^{2}$, Moh. Fanani ${ }^{2}$ \\ ${ }^{1}$ Mahasiswa Biomedik Program Studi Kedokteran Keluarga Pascasarjana Universitas Sebelas Maret \\ ${ }^{2}$ Departemen Psikiatri Universitas Sebelas Maret \\ Korespondensi: dr. Sri Wahyuni, Sp. KJ. Email: dryuni92@gmail.com
}

\begin{abstract}
ABSTRAK
Depresi pasca stroke (DPS) adalah depresi yang mengikuti stroke, merupakan komplikasi paling sering pada stroke dan berdampak gangguan fungsional, penurunan Activity Daily Living (ADL), defisit kognitif, menghambat penyembuhan, meningkatkan mortalitas, terganggunya fungsi motorik, penurunan mobilitas yang progresif, sehingga meningkatkan ketergantungan dan terganggunya integrasi sosial, menyulitkan baik pasien maupun keluarganya, serta menurunkan kualitas hidup. Stroke merupakan penyebab kematian ketiga terbesar di dunia dengan prevalensi terjadinya DPS antara 5\% hingga 63\%. Penatalaksanaan depresi pasca stroke harus komprehensif, meliputi penanganan terhadap stroke maupun depresinya, termasuk faktor faktor risikonya. Penelitian ini bertujuan untuk mengetahui pengaruh Logoterapi Medical Ministry terhadap depresi dan kualitas hidup pasien pasca stroke. Penelitian ini merupakan penelitian analitik eksperimental dengan single blinded randomized controlled trial pre and post-test design. Subjek penelitian adalah pasien pasca stroke yang menderita depresi di Poli Saraf di RS X Surakarta yang memenuhi kriteria restriksi dilaksanakan mulai Desember 2107s/d April 2017. Teknik pengambilan sampel dengan simple random sampling. Instrumen yang digunakan adalah HDRS, WHOQOL. Data yang terkumpul akan diolah dan dianalisis menggunakan software. Data karakteristik umum yang meliputi jenis kelamin, agama, pendidikan, status pekerjaan, DM, HT, lamanya sakit menggunakan uji Chi-Squre hasilnya homogen antara perlakuan dan kontrol, dengan p>0.05. Pada uji statistik perubahan skor pretes-postes HDRS dan WHOQOL perlakuan dibanding kontrol didapatkan nilai $p$ $<0,01$ sehingga terdapat perbedaan yang signifikan antara kelompok perlakuan dan kontrol yaitu penurunan skor HDRS dan peningkatan skor WHOQOL. Kesimpulan penelitian ini adalah Logoterapi Medical Ministry signifikan menurunkan depresi dan meningkatkan kualitas hidup pasien pasca stroke.
\end{abstract}

Kata Kunci: Logoterapi Medical Ministry, HDRS, WHOQOL, DPS

\begin{abstract}
Post-stroke depression (PSD) is the depression following stroke. It is the most frequently complication that has been occurring in stroke and impacting on functional impairment, Activity Daily Living (ADL) decreasement, cognitive deficiency, recovery inhibition, mortality increasement, motor function impairment, and progressive mobility decreasement, thereby increasing dependency and social integration disorder, giving the patients and their family difficulty, and decreasing their quality of life. Stroke is the third leading cause of death in the world with PSD prevalence rate of 5\%-63\%. The management of post-stroke depression should be comprehensive, managing both stroke and depression, including its risk factor. The aims of this research is to find out the effect of Medical Ministry Logotherapy on depression and quality of life post-stroke patients. This research was an analytical experimental research with single blinded randomized controlled trial pre and posttest design. The subject of research was post-stroke patients with depression in Neurological Polyclinic X Hospital of Surakarta fulfilling the restrictive criteria. The research was conducted from December to 2017 to April 2018. The sampling technique employed was simple random sampling. The instruments used were HDRS and WHOQOL. The data collected would be processed and analyzed using software. Data of general characteristics include gender, religion, education, job status, DM, duration of illness, HT with analize of ChiSquare test showed homogeneous between treatment and control, with $p>0.05$. In statistic test, the change of pretes - postest score of HDRS and WHOQOL, in treatment compared with those in control groups obtained p value $<0.01$, so that there was a significant difference between treatment and control groups, the decrease in HDRS and the increase in WHOQOL score. The conclusion of this study are the Logoterapi Medical Ministry is reduce the depression and improve the quality of life of patients post-stroke significantly.
\end{abstract}

Keywords: Medical Ministry Logotherapy, HDRS, WHOQOL, DPS 
How To Cite: Imron, S., Sudiyanto, A., \& Fanani, M. (2019). PENGARUH LOGOTERAPI MEDICAL MINISTRY TERHADAP DEPRESI DAN KUALITAS HIDUP PASIEN PASCA STROKE. Biomedia, 11(1), 18-23. doi:https://doi.org/10.23917/biomedika.v11i1.6168

DOI: https://doi.org/10.23917/biomedika.v11i1.6168

\section{PENDAHULUAN}

Depresi yang mengikuti stroke atau lebih dikenal dengan depresi pasca stroke (DPS). DPS merupakan salah satu komplikasi paling sering pada stroke dan mempunyai konsekuensi negatif yang bermakna terhadap fungsi motorik, defisit kognitif (Kanner, 2005). Depresi pasca stroke menyulitkan baik pasien maupun keluarganya serta menurunkan kualitas hidup (Choi et al., 2012), menghambat penyembuhan, aktifitas sehari hari dan meningkatnya mortalitas (Robinson, 2006).

Depresi pasca stroke juga menyebabkan gangguan fungsional dan memiliki tingkat penurunan ADL ( Activity of Daily Living) yang secara signifikan lebih tinggi di bandingkan dengan pasien dengan defisit neurologis sebanding tapi tanpa depresi. Depresi pasca stroke menyebabkan penurunan mobilitas yang progresif, sehingga meningkatkan ketergantungan dan terganggunya integrasi sosial. Terjadi fenomena timbal balik bahwa depresi mempengaruhi pemulihan ADL dan penurunan nilai ADL mempengaruhi keparahan dan lamanya depresi bahkan meningkatkan angka kematian (Pedroso et al., 2015)

Stroke merupakan penyebab kematian ketiga terbesar di dunia, setelah penyakit jantung dan kanker dengan angka kejadian lebih dari 5,1 juta. Di Amerika setiap 45 menit seseorang mengalami stroke baru. Pada tahun 2020 diperkirakan 7,6 juta orang Amerika akan meninggal karena stroke (Junaidi, 2004). Merurut Riskesdas (2013), stroke merupakan penyebab kematian nomor 1 di Indonesia, insidensi stroke sendiri bervariasi antara 1,5-4 per 1000 populasi (Fitzsimmons, 2007).

Penatalaksanaan depresi pasca stroke harus dilakukan secara komprehensif, yaitu penanganan terhadap stroke maupun depresinya, termasuk mengendalikan faktor faktor risikonya. Menurut penelitian Shao tahun 2013 di Cina, logoterapi (meaning life) mempunyai korelasi yang positif untuk pasien depresi pasca stroke, karena dengan menemukan makna hidup akan menimbulkan kebahagiaan memperbaiki depresi.

Pasien pasca stroke yang mengalami depresi merupakan suatu kondisi yang berat dan multifaktor. Hal itu merupakan stresor dan sumber penderitaan yang sangat berat sehingga pasien merasa berat, sedih, putus asa maupun tidak jarang terpuruk dan kehilangan makna hidupnya, kehilangan kebahagian hidupnya karena sudah bermacam macam usaha yang di lakukan belum mendapatkan hasil yang memuaskan. Dengan logoterapi pasien dibantu menemukan makna hidupnya dengan potensi yang masih dimilikinya. Hidup yang bermakna dapat diperoleh dengan jalan merealisakan tiga nilai kehidupan yaitu nilai kreatif, nilai penghayatan dan nilai besikap (Bastaman, 2007). Pada penderita stroke, nilai bersikaplah yang masih dapat dikembangkan karena nilai kreatif dan nilai penghayatan sudah tidak optimal.

Ada beberapa tehnik logoterapi, tetapi teknik logoterapi yang dipilih dalam studi ini adalah medical ministry, dengan alasan metode ini merupakan salah satu metode yang digunakan untuk menangani masalah somatogenik yang penyebab somatiknya tidak dapat dihilangkan. Pendekatan teknik ini memanfaatkan kemampuan untuk mengambil sikap (attitute) terhadap kondisi diri dan lingkungan yang tidak mungkin diubah (Bastaman, 2007). Dengan logoterapi penederita stroke dibimbing untuk bersikap yang benar untuk menerima sakitnya, menyadari keadaannya dengan mengoptimalkan potensi yang masih dimilikinya. Logoterapi akan menurunkan depresinya sehingga kualitas hidupnya meningkat.

Penelitian tentang pengaruh logoterapi medical ministry terhadap depresi dan kualitas hidup pasien pasca stroke masih sangat terbatas.

\section{METODE}

Metode yang digunakan adalah penelitian analitik eksperimental dengan single blinded randomized controlled trial pre and post-test design (Dahlan, 2016). Penelitian ini dilaksanakan dari Januari 2018 - April 2018 di instalasi rawat jalan bagian Saraf RSUD KOTA Surakarta Provinsi Jawa Tengah.

Dari perhitungan statistik di dapatkan jumlah sampel adalah 30, yang dibagi menjadi dua kelompok yaitu 15 subjek sebagai kelompok 
perlakuan dan 15 subjek sebagai kelompok kontrol. Sampel diperoleh dengan cara pencuplikan sederhana (Simple Random sampling) dengan tehnik undian dibagi menjadi dua kelompok yaitu perlakuan dan kontrol. Penelitian ini dilakukan setelah mendapatkan Ijin kelaikan etik/ Ethical Clearance nomor: 495/VI/HREC/2016. Penelitian dilakukan dengan beberapa langkah, langkah pertama dilakukan pendataan seluruh pasien Stroke yang mengalami depresi di RS X Surakarta. Langkah kedua dilakukan restriksi sampel berdasarkan pembatasan sesuai kriteria inklusi yaitu : pasien pasca stroke yang mengalami depresi di Poli Saraf RS X Surakarta, Usia 18- 80 tahun, pendidikan minimal $\mathrm{SD}$, dapat berkomunikasi dengan baik, bersedia menjadi subjek penelitian, menandatangani surat persetujuan penelitian (Inform Consent) dan kooperatif. Kriteria eksklusi adalah: menderita gangguan mental berat (berdasar wawancara psikiatri), adanya gangguan jiwa berat (psikotik), adanya komorbid penyakit yang berat. Langkah ketiga subjek yang memenuhi kriteria restriksi selanjutnya dilakukan randomisasi dengan diberi nomor undian untuk menentukan yang termasuk dalam kelompok perlakuan dan kelompok kontrol, setiap subjek diberi nomer urut sesuai kedatangan, kemudian ditetapkan bagi subjek yang mendapatkan nomor ganjil maka dimasukkan dalam kelompok perlakuan dan yang genap dimasukkan dalam kelompok kontrol (Sastroasmoro, 2014).

Langkah keempat subjek mengisi persetujuan penelitian, data demografi dan pretes dengan instrumen HDRS dan WHOQOL untuk menilai skor depresi dan kualitas hidupnya. Kelompok perlakuan dilakukan psikoterapi logoterapi sedangkan kelompok kontrol tidak mendapatkan perlakuan logoterapi. Setelah semua sesi logoterapi medical ministry, kedua kelompok dilakukan postes dengan menilai skor depresi dengan HDRS dan kualitas hidup dengan WHOQOL BREF, setelah itu dianalisis menggunakan software.

\section{HASIL DAN PEMBAHASAN}

Penelitian dilakukan di poli saraf RS X Surakarta dengan subjek penelitian pasien pasca stroke yang mengalami depresi dan memenuhi kriteria restriksi. Metode pengambilan sampel dengan pencuplikan sederhana (Simple Random sampling) dengan jumlah sampel 30 orang.

\section{a. Uji homogenistas subjek penelitian}

Sebelum dilakukan analisis lebih lanjut, terlebih dahulu dianalisis karakteristik umum subjek penelitian untuk mengetahui homogenitasnya yang meliputi jenis kelamin, agama, status pekerjaan, pendidikan, DM, umur dan lamanya sakit stroke menggunakan uji ChiSqure, dengan tabel seperti di bawah ini:

Tabel 1. Karakteristik Subjek Penelitian

\begin{tabular}{|c|c|c|c|c|c|c|}
\hline \multirow{2}{*}{ Variabel } & \multirow{2}{*}{ Kategori } & \multicolumn{2}{|c|}{ Perlakuan } & \multicolumn{2}{|c|}{ Kontrol } & \multirow[t]{2}{*}{$p$} \\
\hline & & $\mathbf{n}$ & $\%$ & $\mathbf{n}$ & $\%$ & \\
\hline & laki-laki & 10 & 29.4 & 13 & 38.2 & \multirow{3}{*}{0.271} \\
\hline \multirow{2}{*}{ kelamin } & perempuan & 7 & 20.6 & 4 & 11.8 & \\
\hline & $31-50$ & 3 & 8.8 & 1 & 2.9 & \\
\hline \multirow[t]{2}{*}{ Umur } & $51-70$ & 13 & 38.2 & 12 & 35.3 & \multirow[t]{2}{*}{0.242} \\
\hline & $71-90$ & 1 & 2.9 & 4 & 11.8 & \\
\hline \multirow{2}{*}{ Agama } & islam & 16 & 47.1 & 15 & 44.1 & \multirow{2}{*}{0.545} \\
\hline & kristen & 1 & 2.9 & 2 & 5.9 & \\
\hline \multirow{4}{*}{ Pendidikan } & SD & 10 & 29.4 & 9 & 26.5 & \multirow{4}{*}{0.413} \\
\hline & SMP & 3 & 8.8 & 4 & 11.8 & \\
\hline & SMA/SMK & 2 & 5.9 & 4 & 11.8 & \\
\hline & Diploma & 2 & 5.9 & 0 & 0.0 & \\
\hline \multirow{3}{*}{$\begin{array}{c}\text { Status } \\
\text { pekerjaan }\end{array}$} & PNS & 13 & 38.2 & 17 & 50.0 & \multirow{3}{*}{0.104} \\
\hline & Non PNS & 3 & 8.8 & 0 & 0.0 & \\
\hline & IRT & 1 & 2.9 & 0 & 0.0 & \\
\hline \multirow{2}{*}{$\begin{array}{c}\text { DM } \\
\text { (Diabetes } \\
\text { Melitus) }\end{array}$} & negatif & 13 & 38.2 & 14 & 41.2 & \multirow{2}{*}{0.671} \\
\hline & positif & 4 & 11.8 & 3 & 8.8 & \\
\hline \multirow{2}{*}{$\begin{array}{c}\mathrm{HT} \\
\text { (Hipertensi) }\end{array}$} & negatif & 0 & 0.0 & 1 & 2.9 & \multirow{2}{*}{0.310} \\
\hline & positif & 17 & 50.0 & 16 & 47.1 & \\
\hline \multirow{2}{*}{ Lama sakit } & $=<1$ tahun & 7 & 20.6 & 7 & 20.6 & \multirow{2}{*}{1.000} \\
\hline & $>1$ tahun & 10 & 29.4 & 10 & 29.4 & \\
\hline
\end{tabular}

Pada tabel di atas menggunakan uji ChiSqure ditampilkan karakteristik umum dari kelompok perlakuan dan kelompok kontrol, tidak didapatkan perbedaan bermakna pada jenis kelamin, umur, agama, pendidikan, status pekerjaan, diabetes, hipertensi dan lamanya sakit, dengan nilai probabilitas sebesar $\mathrm{p}>0,05$. Ini menunjukkan bahwa subjek penelitian antara kelompok perlakuan dan kelompok kontrol adalah homogen.

\section{b. Uji normalitas data}

Sebelum dilakukan perhitungan, terlebih dahulu dilakukan perhitungan normalitas data variabel utama untuk memastikan jenis uji statistik yang digunakan. Uji statistik akan menggunakan uji $\mathrm{t}$ tidak berpasangan (Independent Sample t-Test) bila distribusi normal dan menggunakan uji Mann Whitney bila distribusi tidak normal. Uji normalitas data pada penelitian ini menggunakan metode Shapiro wilk pada SPSS. Metode shapiro wilk dilakukan karena data sampel tiap kelompok < 50 (Dahlan, 2016) . Hasil uji normalitas data yang dilakukan pada tiap kelompok menggunakan uji Shapirowilk, didapatkan bahwa ada data yang sebarannya normal ada yang tidak normal sehingga untuk 
menguji perubahan dari pretes ke postes digunakan uji statistik nonparametrik wilcoxon sedangkan untuk menguji perbedaan antara perlakuan dan kontrol digunakan uji statistik nonparametrik Mann Whitney

\section{c. Menguji skor pretes HDRS dan WHOQOL antara kelompok perlakuan dan} kontrol

Sebelum diberi perlakuan yang berbeda, diuji skor pretesnya terlebih dahulu baik pada kelompok perlakuan maupun kelompok kontrol. Hal ini bertujuan untuk mengetahui apakah selama diberi perlakuan berangkat dari keadaan yang sama atau tidak.

Tabel 2. Skor Pretes HDRS Perlakuan Dan Kontrol

\begin{tabular}{cccccc}
\hline Variabel & Kelompok & Rerata & $\begin{array}{c}\mathbf{Z} \\
\text { hitung }\end{array}$ & $\boldsymbol{p}$ & Kesimpulan \\
\hline HRDS & perlakuan & 21.8 & & & \\
& kontrol & 21.6 & -0.174 & 0.862 & Sama
\end{tabular}

Tabel 3. Skor pretes WHOQOL perlakuan dan kontrol

\begin{tabular}{cccccc}
\hline Variabel & Kelompok & Rerata & $\begin{array}{c}\mathbf{Z} \\
\text { hitung }\end{array}$ & $\boldsymbol{p}$ & Kesimpulan \\
\hline WHOQOL & perlakuan & 42.8 & & & \\
& kontrol & 42.4 & -0.329 & 0.742 & sama \\
\hline
\end{tabular}

Dari tabel pretes HRDS diatas diperoleh probalitas sebesar 0,862 sedangkan nilai pretes WHOQOL diperoleh probabilitas sebesar 0.742 . Nilai probabilitas $>0.05$ artinya tidak terdapat perbedaan nilai pretes HDRS dan WHOQOL antara kelompok perlakuan dengan kelompok kontrol.

d. Menguji nilai postes dan selisih pretespostes HDRS dan WHOQOL

Setelah dilakukan logoterapi pada kelompok perlakuan, kemudian dilakukan postes HDRS dan WHOQOL pada kedua kelompok penelitian dengan hasil seperti diagram di bawah ini:

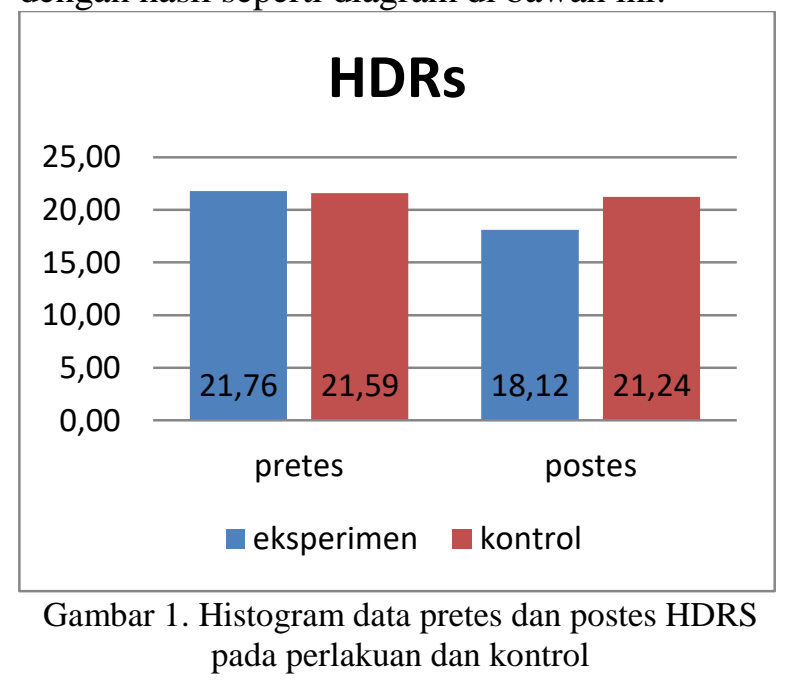

Dari grafik diatas kelompok perlakuan memiliki penurunan yang lebih nyata dibandingkan kontrol. Sedangkan pada kontrol tidak begitu tampak adanya penurunan HRDS bahkan tampak stabil.

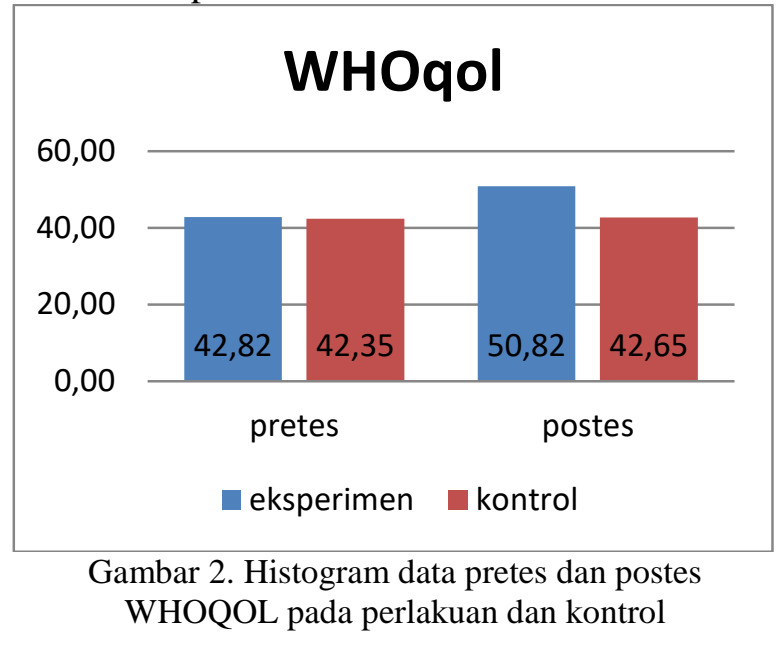

Setelah terapi dengan logoterapi medical ministry pada perlakuan memiliki skor WHOQOL sebesar 50.8 dengan nilai median sebesar 50 sedangkan pada kontrol diperoleh nilai rata-rata sebesar 42.6 dan nilai median sebesar 41, jika dibandingkan maka nilai postes WHOQOL perlakuan cenderung lebih tinggi dibandingkan kontrol

\section{e. Uji kemaknaan logoterapi medical ministry pada perlakuan dibandingkan kontrol}

Tabel 4. Perhitungan selisih pretes dan postes skor HRDS dan WHOQOL perlakuan dibandingkan kontrol.

\begin{tabular}{ccccccc}
\hline Skor & Kelompok & Pretes & Postes & Selisih & $\begin{array}{c}\text { Persentase } \\
\text { Perubahan }\end{array}$ & $\boldsymbol{p}$ \\
\hline \multirow{2}{*}{ HRDS } & \multirow{2}{*}{ perlakuan } & 24.76 & 18.12 & 6.65 & 26.8 & \\
& & \pm 4.04 & \pm 1.87 & \pm 2.67 & & 0.000 \\
& \multirow{2}{*}{ kontrol } & 21.59 & 21.24 & 0.35 & 1.6 & \\
& & \pm 2.58 & \pm 2.56 & \pm 0.49 & & \\
WHOQOL & \multirow{2}{*}{ perlakuan } & 42.82 & 50.82 & 8 & & \multirow{2}{*}{0.000} \\
& & \pm 3.88 & \pm 2.92 & \pm 1.77 & 18.7 & \\
& \multirow{2}{*}{ kontrol } & 42.35 & 42.65 & 0.29 & & \\
& & \pm 3.71 & \pm 3.97 & \pm 0.85 & 0.7 & \\
\hline
\end{tabular}

Pada skor HRDS terjadi penurunan HRDS pada kelompok perlakuan sebesar $6.65 \pm 2.67$ dengan persentase penurunan sebesar 26,8\%. Sedangkan pada kelompok kontrol penurunan HRDS sebesar $0.35 \pm 0.49$ dengan persentase penurunan sebesar $1.6 \%$. jika dibandingka keduanya tampak bahwa penurunan pada kelompok perlakuan jauh lebih besar. Perhitungan secara statistik menggunakan statistik nonparametrik Mann Whitney diperoleh nilai probabilitas sebesar 0.000 . Nilai probabilitas $<0.05(0.000<0.01)$ yang berarti terdapat perbedaan sangat signifikan penurunan HRDS 
antara kelompok perlakuan dengan kontrol. Berdasarkan pernyataan tersebut maka disimpulkan terdapat perbedaan yang sangat signifikan atau sangat bermakna adanya penurunan skor HDRS pada kelompok perlakuan dibandingkan kontrol .

Pada skor WHOQOL terjadi peningkatan skor WHOQOL pada kelompok perlakuan sebesar $8 \pm 1.77$ dengan persentase peningkatan sebesar $18.7 \%$. Sedangkan pada kelompok kontrol peningkatan WHOQOL sebesar $0.29 \pm 0.85$ dengan persentase peningkatan sebesar $0.7 \%$. Jika dibandingka keduanya tampak bahwa peningkatan pada kelompok perlakuan jauh lebih besar. Perhitungan secara statistik menggunakan statistik nonparametrik Mann Whitney diperoleh nilai probabilitas sebesar 0.000 . Nilai probabilitas $<0.01(0.000<0.01)$ yang berarti terdapat perbedaan sangat signifikan peningkatan WHOQOL antara kelompok perlakuan dengan perlakuan kontrol. Berdasarkan pernyataan tersebut maka disimpulkan bahwa terdapat perbedaan yang sangat signifikan antara kelompok perlakuan signifikan lebih baik dalam menurunkan WHOQOL dibandingkan kelompok kontrol.

Prevalensi terjadinya depresi pasca stroke berkisar antara 5\% hingga 63\%, hal ini sering terjadi 3 hingga 6 bulan setelah stroke. Dari 267 penderita stroke di poli saraf RS X kita dapatkan 50 orang atau $18,7 \%$ yang mengalami depresi. Penatalaksanaan depresi pasca stroke harus dilakukan secara komprehensif, yaitu penanganan terhadap stroke maupun depresinya, termasuk mengendalikan faktor faktor risikonya.

Menurut penelitian Shao et al. tahun 2013 di Cina, logoterapi (meaning life) mempunyai korelasi yang positif untuk pasien depresi pasca stroke, karena dengan menemukan makna hidup akan menurunkan depresi dan menemukan kebahagiaan. Dari penelitian penulis sebelumnya dengan metode kualitatif yang di lakukan pada 3 subjek penelitian didapatkan bahwa Logoterapi Medical Ministry efektif menurunkan derajat depresi dan memperbaiki kualitas hidup pasien pasca stoke, pernyataan tersebut sesuai dengan penelitian ini.

Hasil statistik selisih pretes postes perlakuan dibandingkan dengan kontrol didapatkan probabilitas < 0,01 sehingga penurunan HRDS pada kelompok perlakuan sangat signfikan lebih baik dibandingkan penurunan HRDS pada kelompok kontrol. Berdasarkan pernyataan tersebut maka hipotesis 1 diterima yaitu " Logoterapi Medical Ministry sangat signifikan menurunkan depresi pasien pasca stroke ".

Berdasarkan hasil statistik skor selisih pretes postes antara kelompok perlakuan dan kontrol di dapatkan probabilitas $<0,01$, sehingga hipotesis 2 diterima yaitu " Logoterapi Medical Ministry sangat signifikan untuk meningkatkan kualitas hidup pasien pasca stroke".

Problem utama pasien pasca stroke pada penelitian ini hampir sama yaitu: gangguan motorik, sehingga mengganggu aktifitas kehidupan sehari hari bahkan tidak dapat bekerja. Stroke terjadinya mendadak, kronis dan berdampak luas sehingga pasien pasca stroke menjadi sedih, putus asa dan depresi. Tehnik logoterapi membantu subjek untuk menerima kondisi sakitnya dan mengambil hikmah dari sakitnya tersebut dengan modal agama yang dimilikinya, sehingga tidak terpuruk serta timbul semangat lagi sehingga tidak depresi dan kualitas hidupnya meningkat.

\section{SIMPULAN DAN SARAN}

Logoterapi Medical Ministry menurunkan depresi pasien pasca stroke dan meningkatkan kualitas hidup pasien pasca stroke.

Berdasarkan hasil studi ini maka logoterapi Medical Ministry dapat ditambahkan kedalam penatalaksanaan Standart Operating Procedure pada pasien depresi pasca stroke untuk memperbaiki depresi dan kualitas hidupnya.

\section{DAFTAR PUSTAKA}

Bastaman HD, 2007. Logoterapi : Psikologi untuk Menemukan Makna Hidup dan Meraih Hidup Bermakna. Ed. 1, PT Raja Grafindo Persada. Jakarta.

Choi K., Khan K., Choi S., Suh M., 2012. Depresi pasca stroke and Emotional Incontinence Factor Related to acut and Subtance Stage, Neurology J. Seoul National University, Seoul, Korea. vol. 12

Dahlan M S, 2016. Besar Sampel Dalam Penelitian Kedokteran Dan Kesehatan, Epidemiologi, Jakarta. 
Fitzsimmons BF, 2007. Ischemic stroke cerebrovascular disease. In: current diagnosis \& treatment in neurology. NewYork: McGraw Hill Companies; p. 100-105.

Junaidi, I., (2004). Panduan praktis pencegahan dan pengobatan stroke. Jakarta: PT. Bhuana Ilmu Populers.

Kanner MA. 2005. Depression in neurological disorders. United Kingdom: Cambrige Medical Communication; p. 65-72.

Pedroso V, Sauza L, Brunoni A, Teixeira A, 2015, Depresi pasca stroke: clinics, etiopathogenesis and therapeutics, review Artikel, Laboratorio Interdisciplinar de Investigacao Medica (L2M), sala 281, Faculdade de Medicina, Universidade Federal de Minas Gerais, Brazil.

RISKESDAS 2013. Kemenkes, Badan Penelitian dan Pengembangan Kesehatan Kementerian Kesehatan RI.

Robinson R.G., 2006. The Clinical Neuropsychiatry of Stroke, Cambridge University Press, New York, USA

Sastroasmoro S, 2014. Dasar Dasar Metodologi Penelitian Klinis, Edisi ke-5. Penerbit Agung Seto, Jakarta.

Shao J, Shen, Zhang Q, Lin T, 2013.Meaning in life and well-being of older stroke survivors in chinese communities: Mediating effects of mastery and self-esteem, scientific research an academic publisher. 